\title{
Reproduction vs. growth: indications for altered energy fluxes in Lake Constance whitefish through size-selective fishery
}

\author{
Gregor Thomas* and Reiner Eckmann
}

\begin{abstract}
Fisheries-induced evolution (FIE) has been reported for several intensively exploited fish stocks worldwide. Most studies focused on marine populations of high commercial interest, but FIE may also occur in intensively harvested freshwater fish stocks. An example is the whitefish (Coregonts lavaretus) stock of Lake Constance. Previous evidence for FIE in this stock, through the analysis of long-term data sets, showed a long-term effect on growth and reproductive traits in addition to the effects of envirommental factors. In this study, we tested whether growth rates of Lake Constance whitefish were partially hereditary, and whether the results of this experiment support the fisheriesinduced evolution scenario for Lake Constance whitefish. In a laboratory experiment using whitefish larvae, we hypothesized that slow-growing females would produce slow-growing offspring. Our experimental setup allowed rearing of 24 different batches of larvae over 40 days. Growth of larvae was inversely correlated to their weight-at-hatch, and larvae with larger yolk sac volume grew slower. We attribute this result to the intensive size-selective harvest that has occurred in Lake Constance during the past several decades because fish that allocate more energy to reproduction at the expense of growth have an advantage under the present harvest regime over fish that follow the opposite allocation strategy. Oor results are in line with FIE theory and suggest a genetic component to life-history traits of Lake Constance whitefish, whereby slow-growing females tend to produce larvae of a lower growth performance.
\end{abstract}

Keywords: fisheries-induced evolution, Coregonus, hatching, matemity effects, growth rate, lifehistory traits

\section{Introduction}

In recent years, fisheries-induced evolution has become a topic of prime importance. Many highly rated studies report changes of life-history traits in intensively exploited marine and freshwater fish stocks (Iørgensen et al. 2007, KuparinEn \& MERILA 2007, Mollet et al. 2007, Wright 2007, Hutchings \& Fraser 2008). These studies indicate that a size-selective fishery may select for slower growing individuals (HAnson \& ChOUINARD 1992, SwaIn et al. 2007,

Authors' address:

Limnological Institute, University of Konstanz, Mainaustr. 252, 78457 Konstanz, Germany

* Corresponding author, e-mail: gregor.thomas@gmx.de 
THOMAs \& ECKMANn 2007), a decrease in their age and size at maturity (LAw 2000, HeIno et al. 2002, REZnick \& GHALAMBOR 2005), an increase in female fecundity (RunsDorp et al. 2005, THomas et al. 2009) and a decline in genetic diversity within the exploited population (HAUSER et al. 2002). Most studies found evidence for fisheries-induced evolution by analyzing long-term data sets, which in addition to the effects of fishery harvest, may include the effects of changing environmental conditions on fish life-history traits.

Unequivocal proof that selective harvesting leads to rapid evolution that is uncoupled from natural selection mechanisms is difficult to obtain from field studies. Genes coding for the life-history traits in question have not been identified at this time. For example, fish growth is a complex interplay interaction of a variety of metabolic processes and unlikely to be encoded by only a few genes. The laboratory experiment conducted by Conover \& MunCH (2002) with Menidia menidia is the only study that has provided strong evidence for a genetic shift in response to selective harvest. Harvesting $90 \%$ of either the largest or the smallest individuals in a population resulted in significantly different growth rates for the remainder of the population four generations after harvesting. Although the selective pressure was unrealistically strong in this experiment (BRown et al. 2008), the mechanism of selection that the study population was submitted to could presumably apply to other intensively fished species.

In a previous study, we analyzed the growth of whitefish (Coregonus lavaretus) in Lake Constance over a period of 43 years, from 1954-97 (Thomas \& EcKMANN 2007). This time period was characterized by profound changes in the lake's environmental conditions. Anthropogenic eutrophication, which reached its culmination in 1979, and re-oligotrophication in the following years have had far reaching consequences on the entire ecosystem (Eckmann \& Rösch 1998, Sommer et al. 1993, Stralle \& Geller 1998). During this study period, whitefish growth was most strongly influenced by the whitefish standing stock biomass in the lake, whereas the trophic state of the lake was of secondary importance. Further analysis revealed time as a third factor significantly correlated to whitefish growth. We attributed this effect, which amounts to a growth depletion of $6 \mathrm{~mm}$ per ten years during the second year of life, to decades of an intensive size-selective gillnet fishery. The exploitation rate of Lake Constance whitefish is likely to exceed even that of heavily exploited marine fish stocks because Lake Constance is an enclosed system of manageable size. Apart from the fishery, management and stocking policies are potential drivers of rapid evolution of lifehistory traits. Although the evidence for an evolutionary change in the growth performance in the lake's whitefish stock is rather convincing, we cannot exclude that the observed findings result in part, or entirely, from phenotypic plasticity of this species. This is well known for this species (SHItLDS \& UNDERHILL 1993; TURgEON \& BERNANTCHEZ 2003).

CONOVER \& Munch (2002) chose Menidia menidia as a model species because of its small size and short generation time. A similar laboratory experiment with whitefish is difficult to perform because of the fish's size and higher age-at-maturity. For this reason, we selected whitefish with a variety of growth histories and conducted growth experiments with their offspring. We focused primarily on maternal effects and chose female fish, which despite their differences in age, had a similar size. We intended to use males of similar size and age that had experienced a similar growth history. We wanted to explore whether growth rate of whitefish is partially hereditary, and whether the results of this experiment support the fisheries-induced evolution scenario for Lake Constance whitefish. We hypothesized that slow growing females would produce slow growing offspring. 


\section{Materials and methods}

\section{Fish collection, egg fertilization \& incubation}

Ready-to-spawn whitefish were caught overnight in the central part of Upper Lake Constance in early December 2007 with monofilament nylon gillnets of 40 and $44 \mathrm{~mm}$ mesh size (knot-to-knot). Because only nine "ripe and running" females were canght during the first night, the nets were set again the following night. A total of 75 fish of similar length (around $35 \mathrm{~cm}$ total length) were selected for further processing. All fish were measured (standard and total length to $0.5 \mathrm{~cm}$ ) and weighed (to $1 \mathrm{~g}$ ) and seales for age determination were taken from the ventral side caudal to the base of the pectoral fins. Age was determined on site and rechecked to confirm ages by three independent readers at the laboratory several days later, after the scales had dried. The fish were then preserved on crushed ice until the on-site age determination was completed. Our final sample contained 24 females of different age classes and 11 males, which were classified as age 3 (cf. Table 1). Each female's growth was determined by back-calculation of their length at the end of each growing season from scales (Cr. THOMAs \& ECKMANN 2007).

The eggs of each female were stripped into a separate dry plastic bowl, and all males were stripped into a single dry cup and the milt was carefully stirred. With a pipette, the milt was equally distributed among the plastic bowls (approx. $25 \mathrm{~cm}$ diameter) containing 3,000 to 4,000 eggs each. Milt and eggs were mixed and then approx. $200 \mathrm{ml}$ water was added. Because the females were obtained on two different days, we had two groups of males that were used to fertilize the eggs. Fertilized eggs were transported to the laboratory on ice and incubated in a facility consisting of 24 mini Zug jars. Each Zug jar had a volume of approx. $500 \mathrm{ml}$. The incubation system of approx. $300 \mathrm{~L}$ volume was run as a recirculation system. Tap water was cooled to $4-5^{\circ} \mathrm{C}$ in a reservoir and fed into the jars from below, which caused a continuous gentle circulation of the eggs. Every three to four days approximately, $10-20 \%$ of the water in the recirculation system was exchanged. Each Zug jar was housed in a small aquarium, separated from the others by $500 \mu \mathrm{m}$ gauze. Dead eggs were removed daily. A subsample of eggs was taken from each egg batch after water hardening after 2 days to measure egg diameter and dry weight.

\section{Rearing of larvae}

When larvae hatched, they were regularly removed from the Zug jars and the surrounding aquaria where larvae were trapped after being washed out of the jars. The number of larvae that hatched within 24 hours was documented at 4:00 p.m. each day. Because only a small number of larvae from each batch (on average 3,350 eggs per batch) was needed for the rearing experiment, larvae were transferred to the aquaria when the hatch rate exceeded 170 larvae (i.e., about $5 \%$ ) per day. In order to check for possible differences in length at hatching during the time course of the hatching process, the newly hatched larvae from one batch were measured regularly every second day. The time course of the hatching process varied between batches by several days.

Table 1. Age of parental fish used in the experiment according to the age validation in the laboratory. All fish were about the same length $(\sim 35 \mathrm{~cm})$.

\begin{tabular}{lcc}
\hline & \multicolumn{2}{c}{ Parental fish } \\
& Female & Male \\
\hline Age class 2 & 1 & 1 \\
Age class 3 & 14 & 9 \\
Age class 4 & 8 & 1 \\
Age class 5 & 1 & 0 \\
\hline
\end{tabular}


Larvae were reared in aquaria of $13 \mathrm{~L}$ volume that were continuously supplied with tap water at a temperature of $11.5^{\circ} \mathrm{C}$ and tanks were aerated. The artificial light climate was adjusted to the natural light regime in March, i.e., light from 6:30 a.m. to 6:30 p.m., with dusk and dawn lasting for 30 minutes each.

Feeding of larvae started 4 days post hatch $(\mathrm{dph})$. Each day, the larvae were fed with Artemia nauplii begimning at $8: 30 \mathrm{a} . \mathrm{m}$. As the age and size of larvae differed between aquaria, the daily food supply for each batch was adjusted for these differences. Therefore, aquaria were checked regularly between 8:30 a.m. 4:30 p.m., and nauplii were added when their concentration became observably low. In this way we provided an ad libitum food supply for a minimum of 8.5 hours per day. Each morning prior to feeding, the aquaria were cleaned.

When larvae had to be sampled, they were removed prior to the first feeding of that day to keep their stomachs empty for dry weight measurements. Larvae that were sampled were killed with an overdose of TCMP (1.1.1 -Trichlor-2-methyl-2-propanol-Hemilydrate) immediately before measuring. Standard length was measured under a dissection microscope linked to a computer with image analysis soft ware. Additionally, yolk sac size was measured and yolk sac volume calculated according to the methods of BLAXTER \& HEMPEL (1963). All larvae that were sampled from a batch were pooled and dried at $60{ }^{\circ} \mathrm{C}$ for 24 hours (larvae 0 -, 10 and 20-days-old) or for 48 hours (larvae 30-and 40-days-old) and weighed.

\section{Statistical analysis}

The mean dry weight per larva was calculated for each batch on each of the five sampling dates $(0,10$, 20,30 and $40 \mathrm{dph}$ ). An exponential regression $y=a^{*} e^{b^{*}}$ (with $y=$ dry weight; $x=$ time in dph; $a, b=$ constants) was fitted to the five values of each batch. With $r^{2}$ values ranging from 0.987 to 0.995 , the regression coefficient $b$ of the exponential growth curve was chosen as a measure of larval growth. The values of $b$ were tested by multivariate statistics (multiple linear regression model, using JMP) against several factors characterizing the different batches (egg size, egg dry weight, dry weight of larvae at hatching, length of newly hatched larvae, yolk sac volume, growth rate and age of mothers).

\section{Results}

Larvae started hatching February 12 and ended March 27. The mean time of reaching the point at which $50 \%$ of larvae per batch had hatched was 86 days post-fertilization (minimum 75 , maximum 94 days). The average duration from the point at which hatching started until $90 \%$ of larvae per batch had hatched was 17.8 days (minimum 10 , maximum 30 days).

Larvae grew from a mean length-at-hatching of $10.8 \mathrm{~mm}$ to a mean length of $27.5 \mathrm{~mm}$ in 40 days (mean values: $10 \mathrm{~d}=13.4 \mathrm{~mm} ; 20 \mathrm{~d}=18.3 \mathrm{~mm}$ and $30 \mathrm{~d}=22.4 \mathrm{~mm}$ ) (Fig. 1). Differences in dry weight between batches became apparent after 30 and $40 \mathrm{dph}$ (Fig. 2). The final dry weight of larvae ranged from 29.2 to $43.5 \mathrm{mg}$ among larval batches. Growth in terms of weight was well described by an exponential model, whereas growth in terms of length was almost linear during the 40-day-experiment.

Larvae that hatched earliest were around $10 \%$ smaller than larvae that hatched later from the same batch of eggs (Fig. 3), suggesting that pre-hatch larvae continue to grow until they emerge from the eggs. For this reason, it was of particular importance to control which phase of the hatching process larvae were taken for stocking into the rearing aquaria. We determined the point in time at which $50 \%$ of larvae per batch had hatched and used this date to determine when larvae were to be stocked into the aquaria (Fig. 4). 


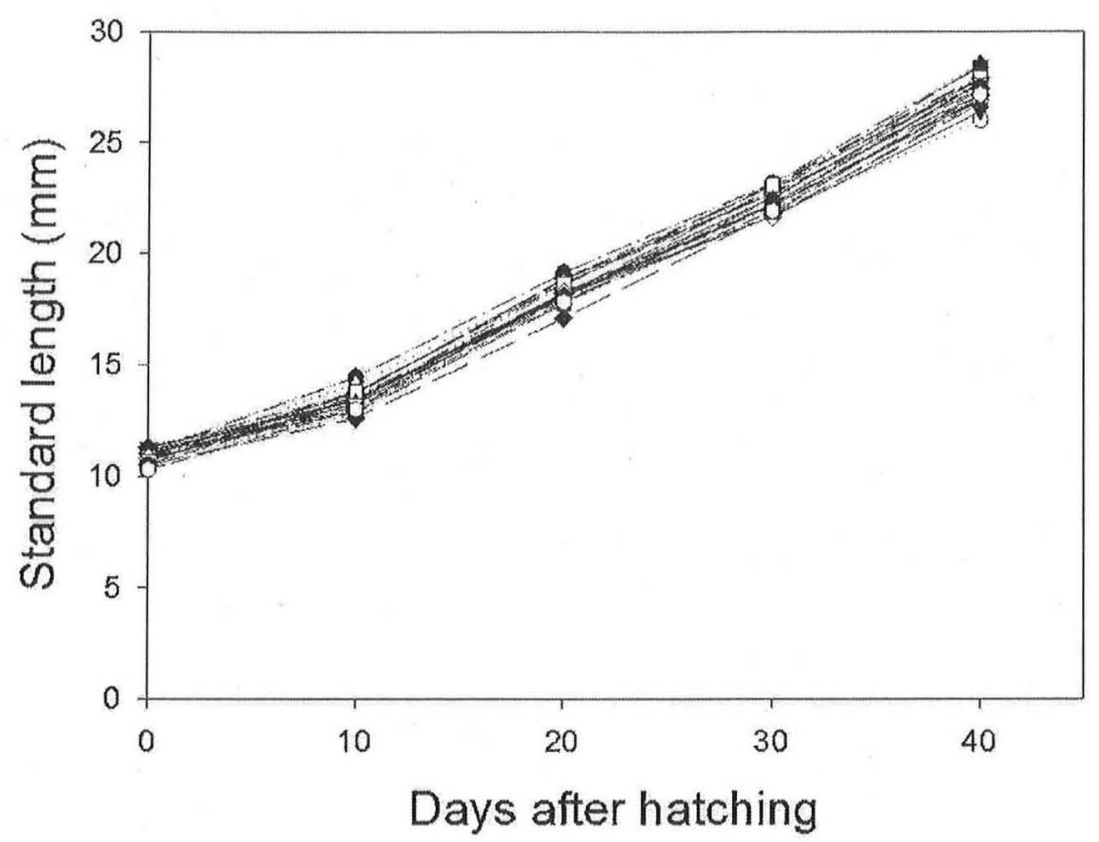

Fig. 1. Standard length of larvae from all 24 batches measured in 10-day time intervals.

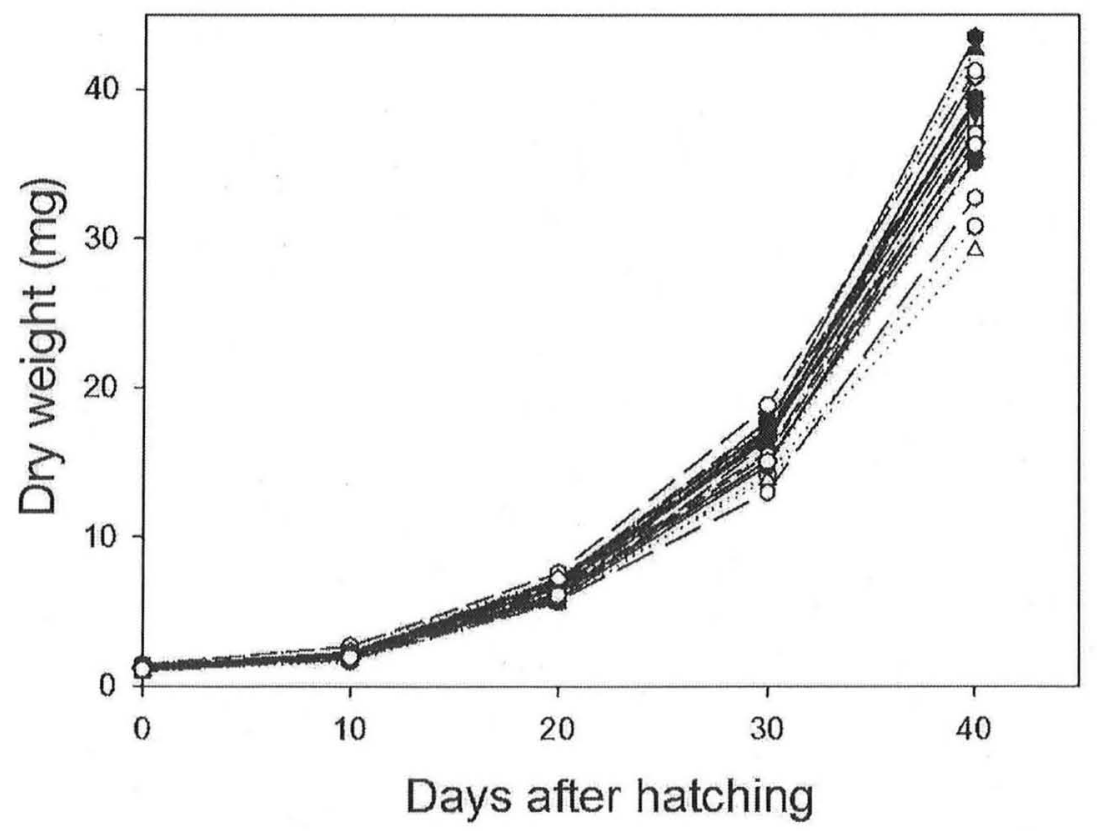

Fig. 2. Dry weight of larvae from all 24 batches measured in 10-day time intervals. 


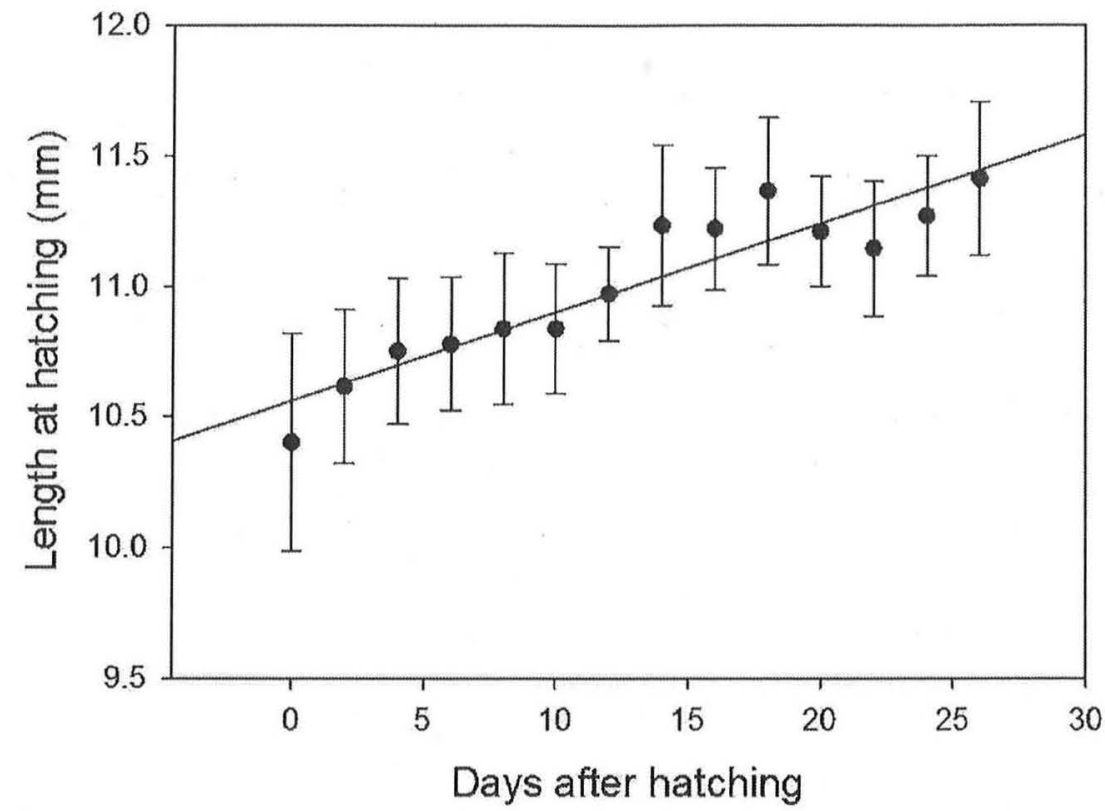

Fig. 3. Hatching length of larvae originating from the same batch. Larvae continued growing inside the eggs and successively hatched at larger size.

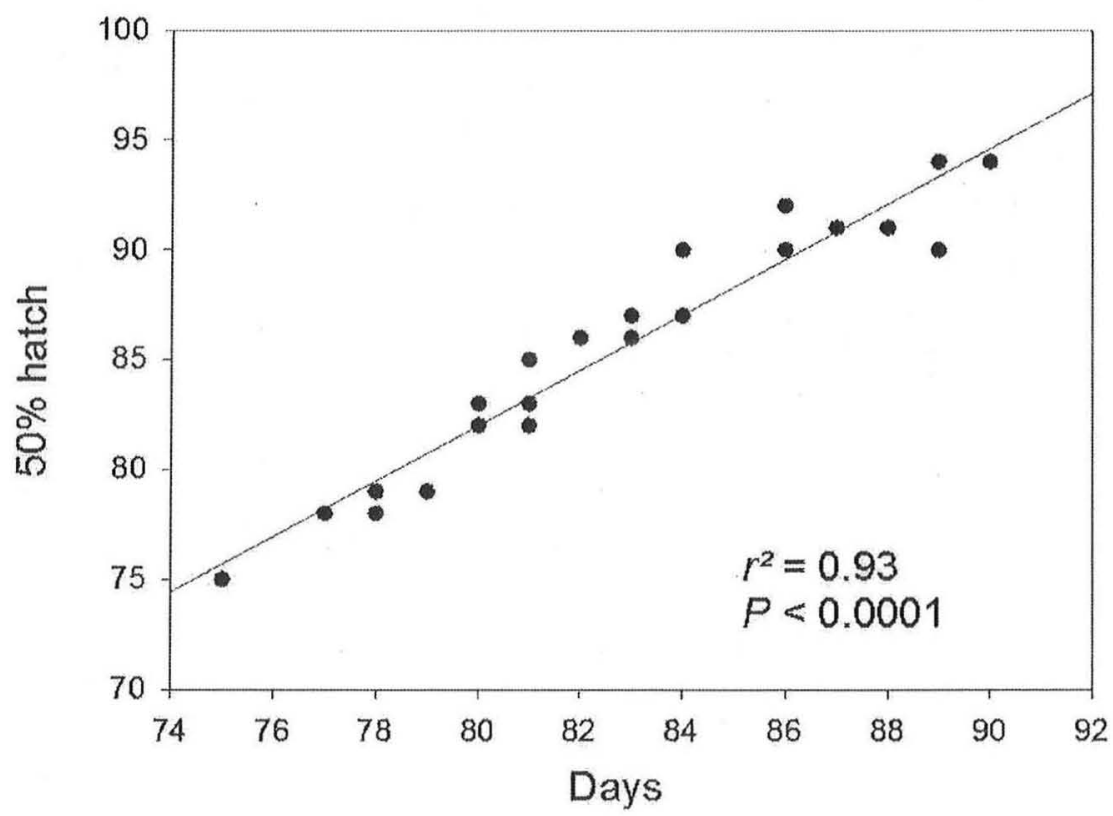

Fig. 4. Days until the mid-point of hatching ( $50 \%$ of larvae hatched) versus the time from fertilization until larvae were stocked into the rearing aquaria. 


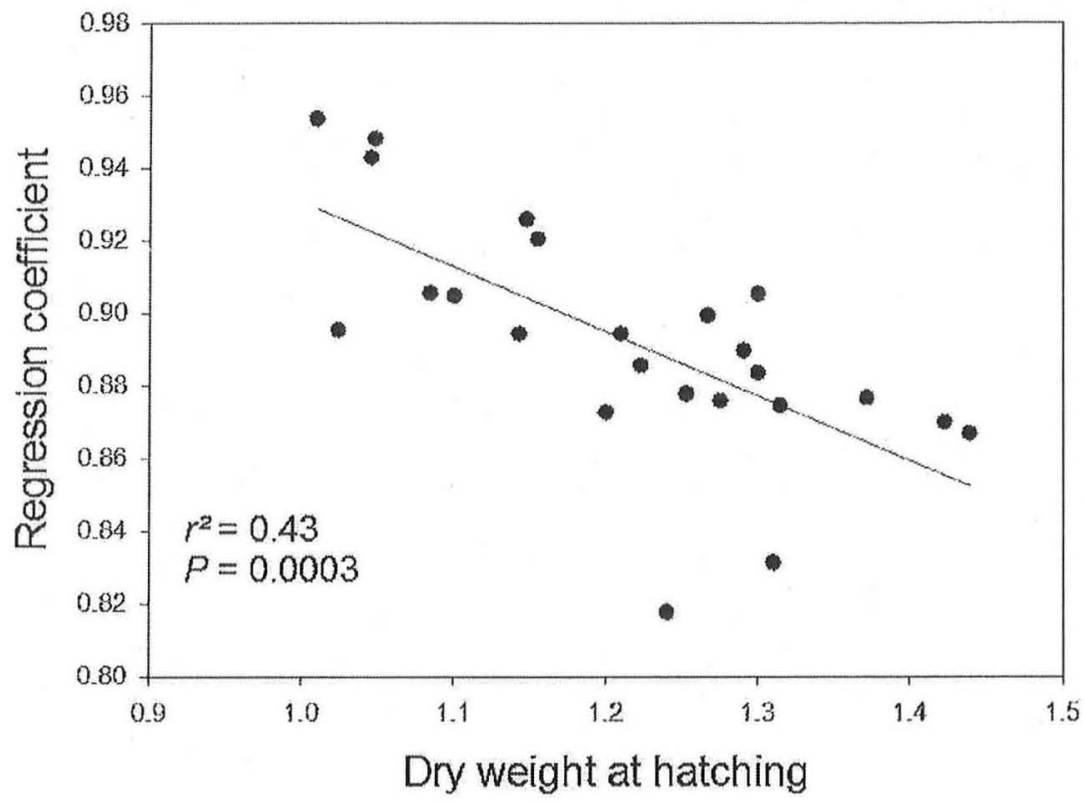

Fig. 5. Regression coefficients of the exponential growth curves for all 24 batches of larvae versus dry weight of larvae at hatching.

The multivariate analysis identified a strong inverse correlation between the larvae's weight-at-hatch and their growth in terms of weight (Fig. 5). Larvae of higher weight-athatch grew slower than larvae of lower weight-at-hatch $\left(r^{2}=0.43 ; P=0.0003\right)$. There were also inverse correlations between growth in terms of weight and yolk sac volume $\left(r^{2}=0.40\right.$; $P=0.0006)$, egg dry weight $\left(r^{2}=0.36 ; P=0.0012\right)$ and egg diameter $\left(r^{2}=0.14 ; P=0.038\right)$, whereas the time of hatching was not related to egg dry weight $\left(r^{2}=0.05 ; P=0.14\right)$. The negative correlation between growth and larval weight-at-hatch can be attributed mainly to differences in yolk sac volume between larvae from different batches, because weight-athatch and yolk sac volume were strongly correlated $\left(r^{2}=0.63 ; P<0.0001\right)$. Furthermore, growth of larvae was positively correlated with the time between fertilization and the midpoint of hatching; larvae from batches that hatched later grew better $\left(r^{2}=0.30 ; P=0.0032\right)$. The yolk sac volume of larvae declined with increasing time from fertilization to hatching $\left(r^{2}=0.50, P<0.0001\right)$.

Combining all results described above into the multivariate analysis, $56 \%$ of the variability in larval growth can be attributed to egg dry weight $(F=12.6 ; P=0.0019)$ and to the number of days between fertilization and the mid-point of hatching, when larvae were stocked into the rearing aquaria $(F=11.1 ; P=0.0032)$. We chose egg dry weight as a measure for larval quality in this final analysis, because yolk sac volume decreases as larvae continue to grow until hatching. This is justified as yolk sac volume is strongly correlated $\left(r^{2}=0.77\right)$ with egg dry weight $(F=32.2 ; P<0.0001)$ and with the number of days between fertilization and stocking $(F=27.0 ; P<0.0001)$. Larvae hatching from heavier eggs grew slower, whereas 
larvae from batches with longer embryonic development had smaller yolk sacs at hatching but grew better. Furthermore, the growth rate of females was inversely related to weight-athatching of their progeny $\left(r^{2}=0.19, P<0.035\right)$, i.e., slow growing females produced slow growing larvae.

\section{Discussion}

Our analysis showed that larvae with higher weight-at-hatching showed better growth performance when compared to larvae with lower weight-at-hatching, and that length-at-hatching was not correlated with subsequent larval growth. Because weight-at-hatching and yolk sac volume were strongly related, we concluded that larvae that have more energy reserves also have lower growth rates.

On first glance, this result is rather surprising as it is commonly accepted that larvae with larger energy stores have better starting conditions and grow faster than larvae with lower energy stores. For example, older females of Sebastes melanops produce eggs with higher lipid content, and larvae originating from these eggs grow up to 3 times faster than offspring from younger females (BERKELEY et al. 2004). RANA (1985) showed that larvae hatching from larger eggs have higher starvation resistance than larvae hatching from smaller eggs. For North Sea plaice Pleuronectes platessa, HeATH et al. (1999) and KFnNEDY et al. (2007) found higher growth rates of larvae with larger yolk sacs, although they also had smaller size-athatching.

For populations that have evolved in the absence of fishing pressure or in the presence of low fishing pressure, a positive correlation between yolk energy reserves and growth of larvae is easily understood, but in populations facing intense, size-selective exploitation, this correlation can be reversed. This seems to be the case with Lake Constance whitefish, and we will discuss our results in the light of FIE theory. Fish have to change their energy allocation continuously in order to adapt to changing environmental conditions. Basically, surplus energy can be invested into either reproduction or somatic growth (SCHULTZ \& WARNER 1991, Jennings \& Philipp 1992). Thus, we can distinguish between a "growth" and a "reproductive" strategy of energy allocation, which is probably genetically determined or partially genetically determined. The "growth" life history strategy implies that fish invest a larger proportion of surplus energy into somatic growth than reproductive output. They benefit from growing quickly through the early life stage where there is high predation from gape-limited predators. They can also use a wider prey spectrum due to their larger gape (TIMmERman et al. 2000), and swimming speed and performance improves with increasing body size (LEIS et a1. 2007).

In contrast, the "reproductive" strategy favors energy allocation to reproductive traits at the expense of somatic growth. The impact this strategy has on the fish's reproductive traits includes younger age at maturity, higher fecundity, and better egg and larval quality. The advantage of this strategy is that more larvae with higher energy content are produced. In an environment with a distinctly higher mortality risk above a critical size, the "reproductive" strategy is likely to be more successful in the long run because fish produce more offspring before their mortality risk increases. RusNsDore et al. (2005) pointed out that the fishery can affect these general allocation strategies significantly. 
For many fish species, the commercial fishery can become the dominant cause of mortality, whereas natural mortality can become less relevant. In this situation, a shift towards the "reproductive" strategy will occur. Besides environmental factors however, the genetic background influences the development of reproductive traits as well as early larval performance (HeAtr et al. 1999, Perry et al. 2004). A size-selective fishery may modify reproductive traits, such as a shift towards younger age and smaller size at maturity (LAw 2000, HeINo et al. 2002) and towards higher fecundity (RusNSDoRP et al. 2005). Along with an increase in reproductive effort, the population growth rate will decline. Under strong fishing pressure, growing slowly confers an advantage considering that growing faster means dying earlier. Hence, a size-selective fishery of high intensity will favor the "reproductive" strategy.

The results of our experiment are consistent with the "reproductive" strategy. Slow growing females have a higher reproductive investment. This is reflected in the production of large and energy rich eggs. Larvae hatching from larger eggs are heavier because they have larger yolk sacs.

As paternal effects on the performance of early larval stages are considered to be insignificant (HeAth et al. 1999), we assume that the growth rate of larvae in our experiment is mainly due to maternal effects. The offspring of slow-growing female whitefish grew slow as well, suggesting a genetic component to growth performance in Lake Constance whitefish. Slow growth may carry a great deal of disadvantages, but these can be compensated by higher resistance to starvation (RANA 1985, HeATH et al. 1999), an hypothesis which we did not test in our experiment.

The correlation between maternal growth and the growth performance of their offspring was not very strong $\left(r^{2}=0.19\right)$ in our experiment, albeit the response was statistically significant. The factors controlling the growth rate of female whitefish, however, are manifold and cannot be confined to a genetic component alone. Hence, the main uncertainty in this analysis is that we do not know to which degree the growth of female whitefish is controlled genetically and to which degree environmentally. As each fish has its own individual growth history, experiencing slightly different environmental conditions during its ontogeny, genetic effects on growth rate can become blurred.

The second observed effect, that later hatched larvae grew faster, might be evolutionarily adaptive via a different mechanism. Because the duration of embryogenesis until hatching was unrelated to egg dry weight and to size-at-hatching, the hypothesis that larger larvae need more time until hatching can be discarded. Larvae hatching later in spring may be at. a disadvantage compared to larvae that hatch earlier in the spring. The former appear in the epilimnion at a time when the latter have already started to improve their prey capture success (BRAUM 1964) and to exploit the limited zooplankton resources. Late larvae can only compete successfully with their counterparts when they are able to utilize the available resources more efficiently, thereby compensating their initial disadvantages. In summary, hatching late and growing fast are life history traits that seem to be linked to each other, and this combination of traits is more likely to be expressed in larvae originating from fast-growing mothers. The conclusions drawn from our results should be treated with caution considering the small number of $\mathrm{gg}$ batches (24) studied in this experiment. Our findings, however, are in line with fishery-induced evolution (FIE) theory and support the previously hypothesized FIE scenario for Lake Constance whitefish. 


\section{Acknowledgements}

Many thanks to Myriam Schmidt, who put a lot of time and effort towards the care of eggs and larvae and the measurement of larvae. Thanks to Mark Schuhmann, who helped feeding the larvae on the weekends. We thank Andreas Revermann and helpers for catching the fish. Shannon O'Leary gave helpful comments while correcting the English.

\section{References}

Berkeley, S.A., Chapman, C., Sogard. S.M. (2004): Maternal age as a determinant of larval grow th and survival in a marine fish, Sebastes melanops, - Ecology 85: 1258-1264.

BLAXTER, J.H.S., HEMPEL, G. (1963): The influence of egg size on herring larvae (Clupea harengus L.). - J. Cons. Perm. Int. Explor. Mer. 28: 211-240.

BRAuM, E. (1964): Experimentelle Untersuchungen zur ersten Nahrungsaufnahme und Biologie an Jungfischen von Blaufelchen (Coreganus wartmanni Bloch), Weissfelchen (Coregonus fera Jurine) und Hechten (Esox lucius L.). - Arch. Hydrobiol. 28, Suppl. 5: 183-244.

Brown, C.J., HOBDAY, A.J. , ZIEGLER, PE., WELSFORD, D.C. (2008): Darwinian fisheries science needs to consider realistic fishing pressure over evolutionary time scales. - Mar. Ecol.-Prog. Ser. 369: $257-266$.

Conover, D.O. \& Munch, S.B. (2002): Sustaining Fisheries Yields Over Evolutionary Time Scales. Science 297: 94-96.

EcKMANn, R. \& Rösch, R. (1998): Lake Constance fisheries and fish ecology. - In: Bäuerle, E. and Gaedke, U. (eds.): Lake Constance, Characterization of an ecosystem in transition. - Arch. Hydrobiol. Spec. Issues Advanc. Limmol 46: 285-301.

Hanson, J.M. \& Chounard, G.A. (1992): Evidence that size-selective mortality affects growth of Atlantic cod (Gadus morhua L.) in the southem Gulf of St Lawrence. - J. Fish Biol. 41: $31-41$.

Hauser, L., Adcock, GJ., Smith, PJ., Carvalho, B.R., J.H., G.R. (2002): Loss of microsatellite diversity and low effective population size in an overexploited population of New Zealand snapper (Pagrus auratus) .- P. Natl. Acad. Sci. USA. 99: 11742-11747.

HEATH, D.D., FOX, C.W., HeATH, J.W. (1999): Maternal effects on offspring size: variation through early development of chinook salmon. - Evolution 53: 1605-1611.

HEINO, M., DIECKMANN, U., GODø, O.R. (2002): Measuring probabilistic reaction norms for age and size at maturation. - Evolution 56: 669-678.

HutCHINGS, J.A. \& FRASER, D.J. (2008): The nature of fisheries- and farming-induced evolution. - Mol. Ecol. 17: 294-313.

JENNINGS, M.J. \& PHILPP, D.P. (1992): Reproductive investment and somatic growth rates in longear sunfish. - Environ. Biol. Fish. 35: 257-271.

Jørgensen, C., Enberg, K., Dunlop, E.S., Arlinghaus, R., Boukal, D.S., Brander, K., Ernande, B., Gardmark, A., Johnston, F., Matsumura, S., Pardoe, H., RaAb, K., Sllva, A., Vainikka, A., Dieckmann, U., Heino, M., RuJnsdoRp, A.D. (2007): Managing evolving fish stocks. - Science 318: $1247-1248$.

KENNEDY, J., GEFFEN, A.J., NASH, R.D.M. (2007): Maternal influences on egg and larval characteristics of plaice (Pleuronectes platessa L.). - J. Sea Res. 58: 65-77.

KupARINEN, A. \& Merila, J. (2007): Detecting and managing fisheries-induced evolution. - Trends Ecol. Evol. 22 (12): 652659.

LAW, R. (2000): Fishing, selection, and phenotypic evolution. - ICES J. Mar. Sci. 57: 659-668.

LeIs, J.M., HAY, A C. LOCKETT, M.M., CHEN, J-P., FANG, L-S. (2007): Ontogeny of swimming speed in larvae of pelagic-spawning, tropical, marine fishes. - Mar. Ecol-Prog. Ser 349: 255-267.

Mollet, F.M., KRAAK, S.B.M., RIINSDORP, A.D. (2007): Fisheries-induced evolutionary changes in maturation reaction norms in North Sea sole Solea salea. - Mar. Ecol - Prog. Ser. 351: 189-199.

PERRY, G.M.L., Bernatchez, L., LAPL.ATTE, B., AUdet, C. (2004): Shifting patterns in genetic control at the embryo-alevin boundary in brook charr. - Evolution 58: 2002-2012. 
RANA, K.J. (1985): Influence of egg size on the growth, onset of feeding, point-of-no-return, and survival of unfed Oreochromis mossambicus firy, - Aquaculture 46: 119-131

REZNICK, DN. \& GHAI.AMBOR, C.K. (2005): Can commercial fishing cause evolution? Answer from guppies (Poecilia reticulata). - Can. J. Fish. Aquat. Sci. 62: 791-801.

RUNSDORP, A.D., GRIFT, R.E., KRAAK, S.B.M. (2005): Fisheries-induced adaptive change in reptoductive investment in Notth Sea plaice (Pleuronectes platessa) - Can. J. Fish. Aquat. Sci, 62: 833-843.

SCHULTZ, E.T. \& W ARNer, R.R. (1991): Phenotypic plasticity in life-history traits of female Thalassoma bifasciatum (Pisces: Labridae): 2. Correlation of fecundity and grow th rate in comparative studies.Environ. Biol. Fish. 30: 333-344.

SHELDS, B.A. \& UNDERHILL, J.C. (1993): Phenotypic plasticity of a transplanted population of dwarf cisco, Coregonus artedii. - Environ. Biol. Fish. 37: 9-23.

SOMMER, U., GAEDKE, U., SchwEIzER, A. (1993): The first decade of oligotrophication of Lake Constance -II. The response of phytoplankton taxonomic composition. - Oecologia 93(2): 276-284

Straile, D. \& Geller, W. (1998): The response of Daphinia to changes in trophic status and weather patterns: A case study from Lake Constance. - ICES J. Mar. Sci. 55(4): 775-782.

SWAIN, D.P., SinClaIR, A.F., Hanson, J.M. (2007): Evolutionary response to size-selective mortality in an exploited fish population. - P. Roy. Soc. Lond. B Bio. 274: 1015-1022.

THOMAs, G. \& EcKMANN, R. (2007): The influence of eutrophication and population biomass on common whitefish (Coregonus lavaretus) growth - the Lake Constance example revisited. - Can. J. Fish. Aquat. Sci. 64: 402-410.

THomas, G., Quoss, H., Hartmann, J., Eckmann, R. (2009): Human-induced changes in the reproductive traits of Lake Constance common whitefish (Coregonus lavaretus). - J . Evol. Biol . 22: 88-96.

Timmerman, C.M., Annett, C.A., Bail.ey, C.F. (2000): Determination of factors limiting prey size swallowed by larval and small juvenile largemouth bass. - -T. Am. Fish. Soc. 129: 618-622

TURGEON, J. \& BERNANTCHEZ, L. (2003): Reticulate evolution and phenotypic diversity in North American ciscoes, Coregonus ssp. (Teleosteii: Salmonidae): implications for the conservation of an evolutionary legacy. - Conserv. Genet. 4: 67-81.

WRIGHT, P. J. (2007): Understanding the maturation process for field investigations of fisheries-induced evolution. - Mar. Ecol.-Prog. Ser. 335: 279-283. 